\title{
Bioactive Fraction from Datura stramonium Linn. Promotes Human immune Cells Mediated Cytotoxicity towards Lung and Breast Cancer Cells
}

\author{
Aditi Gupta', Sunil Kumar², Neeraj Mahindroo ${ }^{2}$, Reena Vohra Saini ${ }^{1 *}$ \\ 'Animal Biotechnology Laboratory, Faculty of Applied Sciences and Biotechnology, Shoolini University, Himachal Pradesh, INDIA. \\ 2Pharmacology Laboratory, Faculty of Pharmaceutical Sciences, Shoolini University, Himachal Pradesh, INDIA.
}

\begin{abstract}
Aim: The aim of the present study was to evaluate immune modulatory effect of fractions of $D$. stramonium $L$. leaves on human peripheral blood mononuclear cells (PBMC) followed by assessment of cytotoxic abilities of immunomodulated PBMC toward cancer cells. Material and methods: Bioassay (PBMC proliferation) guided fractionation of methanolic leaf extract of $D$. stramonium was performed to get active fraction and LC-MS was performed to identify the phytocompounds present in the bioactive fraction. The immunomodulatory potential of $D$. stramonium active fraction was assessed by i) MTT microcytotoxicity assay using A549 (lung carcinomas) and MCF-7 (breast cancer) cell lines and ii) analyzing the production of IL-2 and IFN- $\gamma$ by human PBMC in the presence of active fraction. Results: Chromatographic fractionation guided by PBMC proliferation assay of D. stramonium extract resulted in bioactive fraction (fraction-10) exhibiting significant immunostimulatory activity $\left[E C_{50}=19.1 \pm 1.5(\mu \mathrm{g} / \mathrm{ml})\right]$ on human blood lymphocytes. Fraction-10 pretreated PBMC displayed enhanced cytotoxicity towards A549 and MCF-7 $(59 \% \pm 2.1 \%$ and $62 \% \pm 2.3 \%$ at $1: 20$ effector:target ratio respectively). Moreover, fraction-10 also enhanced the secretion of IL-2 (8 fold) and IFN- $\gamma(10$ fold) by human PBMC. The preliminary
\end{abstract}

phytochemical analysis of fraction-10 from $D$. stramonium showed the presence of terpenoids and steroids. LC-MS analysis depicted presence of four major phytoconstituents in fraction-10 as daturaolone, daturadiol, stigmasterol and sitosterol with corresponding mass spectrum $(\mathrm{m} / \mathrm{z})$ of 440, 442, 412 and 414 respectively. Conclusion: The present report concluded that active fraction-10 of $D$. stramonium possesses potential immunostimulators that are capable of enhancing anticancer responses of human blood lymphocytes.

Key words: Immunomodulation, PBMC, Anticancer, Cytokine, Cytotoxic, Datura stramonium.

Corresponding author: Dr. Reena V. Saini, Faculty of Applied Sciences and Biotechnology, Shoolini University, Solan, Himachal Pradesh, INDIA.

Phone: +91 8894568244

Email: reenavohra10@gmail.com

DOI : 10.5530/pj.2016.5.4

\section{INTRODUCTION}

Cancer is a dreadful disease which is continuously spreading with enhanced mortality rate. ${ }^{1}$ Immunomodulation has become as a revolutionary therapy for cancer which has been designed as an alternative and complementary to the conventional treatments. Medicinal plants have been studied with greater interest in the recent years as they have found to possess immunomodulatory activity that has been used in the treatment of many human ailments. ${ }^{2} D$. stramonium L. is an annual herb from the Solanaceae family which is commonly known as Thorn apple or Jimson weed. It has been reported that $D$. stramonium possesses many therapeutic properties like anti-inflammatory, antiasthematic and antioxidant activities. ${ }^{3-5}$ D. stramonium is a rich source of tropane alkaloids like anticholinergic drugs atropine and scopolamine andalso consists of many other active phytochemical constituents like flavonoids, terpenoids, steroids, withanolides, glycosides, saponins, tannin, carbohydrates which have shown various biological activities. ${ }^{6}$ Ahmad et al., (2009) reported that aqueous leaf extract of D. stramonium showed cytotoxic effects against head and neck, breast and lung cancer cell lines with exposure for 24 to 48 h. ${ }^{7}$ Datura lactones isolated from D. quercifolia have shown immunomodulatory activity on mouse splenocytes with enhanced antibody production, $\mathrm{T}$ and $\mathrm{B}$ cells activation and increased cytokine secretion. ${ }^{8}$ The immunomodulatory effect of total and protein extract from D. stramonium has been studied by Daoudi et al., (2013) on mouse splenocytes and showed significant immunostimulatory activity. ${ }^{9}$ To the best of our knowledge this is the first study demonstrating immunostimulatory activity of D. stramonium on human PBMC leading to cancer cell killing. In this context, bioassay guided fractionation ${ }^{10}$ of D. stramonium methanolic leaf extract was performed to obtain bioactive fraction. The effect of $D$. stramonium bioactive fraction was analysed on human peripheral blood lymphocytes by employing a whole cell assay system ${ }^{11}$ where A549 and MCF-7 cancer cells were used as targets. LC-MS analysis was also carried out to determine the major components present in the bioactive fraction.

\section{MATERIAL AND METHODS}

Reagents and chemicals

DMEM (HiMedia, India), RPMI- 1640 (HiMedia, India), penicillin and streptomycin (HiMedia, India), FBS (Gibco, US), DMSO and Con A (HiMedia, India), MTT (HiMedia, India), methanol, chloroform, hexane and ethyl acetate (HiMedia, India).

\section{Collection of Plant material}

The leaves of D. stramonium L. were collected at Nauni campus, Dr. Y. S. Parmar University of Horticulture and Forestry, Himachal Pradesh, in August 2014. The botanical identity was confirmed by Department of Forest Products, Dr. Y.S. Parmar University of Horticulture and Forestry, Nauni, Solan (H.P.). Voucher specimens were deposited with the Herbarium and are entered in UHF- Herbarium Field book no. 2916, Receipt No. 072.

\section{Preparation of plant extracts and fractions}

D. stramonium leaves were air dried $(6 \mathrm{Kg})$ and methanolic extract was prepared by hot continuous extraction at $60^{\circ} \mathrm{C}$ with $150 \mathrm{ml}$ of methanol. Further fractionation was performed by acidifying the crude extract (30 g) with $5 \% \mathrm{HCl}$ and then purified with chloroform $(40 \mathrm{ml})$ to obtain 
non-alkaloid fraction (10 g). Alkalised the remaining extract with ammonia solution and again extracted with successive portions of chloroform $(40 \mathrm{ml})$ to get alkaloid fraction $(7 \mathrm{~g}) .{ }^{12}$ The non-alkaloid fraction was subjected to column chromatography on silica gel (60-120 mesh) eluting with chloroform:methanol $(3: 2 \mathrm{v} / \mathrm{v})$ and resulted into four sub fractions. Bioactivity of these four sub fractions were analyzed by proliferation assay. Bioactive sub fraction (F2) (5 g) was further chromatographed using a gradient elution with mixture of $n$-hexane and ethyl acetate and a total of thirteen fractions were obtained. All thirteen fractions were screened via MTT assay.

\section{Phytochemical analysis of bioactive fraction-10 from D. stramonium}

Various biochemical tests were performed on bioactive fraction-10 of D. stramonium for the preliminary screening of phytochemicals. The following tests were then performed on fraction-10 for the presence of phytocompounds, ${ }^{13,14}$

Alkaloids: Few drops of Mayer's reagent were added to the fraction-10. Formation of white or pale yellow colour indicates the presence of alkaloids.

Carbohydrates: Few drops of benedict's reagent were added to the fraction-10 and then boiled in water bath for 2 minutes. Formation of yellow, green or brick red colour indicates the presence of carbohydrates.

Terpenoids: $2 \mathrm{ml}$ chloroform was added to the dried powder of fraction-10 followed by few drops of sulphuric acid. Solution became red which indicates the presence of terpenoids.

Steroids: Dried powder of fraction-10 was dissolved in chloroform (2ml) followed by ten drops of acetic anhydride and then two drops of conc. sulphuric acid was added. Colour of solution changed from red to blue indicates the presence of steroids.

Flavonoids: Fraction-10 was treated with a few drops of lead acetate solution. Formation of a yellow colour precipitate indicates the presence of flavonoids.

Tannins: Formation of blue-green colour with few drops of $\mathrm{FeCl}_{3}$ solution to the fraction-10 indicates the presence of tannin.

\section{LC-MS analysis of fraction-10}

The LC-MS analysis was performed to identify the compounds present in bioactive fraction (fraction-10). Separations were made on C-18 column $\left(\right.$ Atlantis $\left.^{\mathrm{TM}}\right)(5 \mu \mathrm{m}$ particle size, L $\times$ I.D. $15 \times 4.6 \mathrm{~mm})$ using acetonitrilewater (9:1) isocratic elution. The flow rate was set at $0.5 \mathrm{ml} / \mathrm{min}$ and the detection was made by using a Photodiode array detector (PDA). Mass analysis was done using Electro-spray ionization (ESI) mode (3000 voltage and $\mathrm{pH}$ range2-9 etc). The compounds were identified with the help of spectral data and by comparing with reports given in the literature. ${ }^{15}$

\section{Cell lines}

Human cancer cell lines A549 (lung) and MCF-7 (breast) were purchased from the National Centre for Cell Science, Pune, India. Cell lines were maintained in DMEM supplemented with penicillin (100 units/ $\mathrm{ml})$, streptomycin $(100 \mathrm{mg} / \mathrm{ml})$ and $10 \%$ FBS. Cells were incubated at $37^{\circ} \mathrm{C}$ in a humidified, $5 \% \mathrm{CO}_{2}$ atmosphere.

\section{Preparation of PBMC}

Blood (15-20 ml) was collected from healthy human donors and the present work has been carried out in compliance with the ethical committee guidelines of Shoolini University with IEC no. SUIEC/14/01. PBMC were isolated from blood using Lymphocyte Separation Media (HiMedia) according to manufacturer's instructions. ${ }^{16}$ The lymphocytes were washed with PBS and resuspended in RPMI-1640 media supplemented with $10 \% \mathrm{FBS}$ and antibiotics. Cell counting was performed to determine the PBMC number with equal volume of trypan blue.

\section{Cell viability Assay}

The effect of plant extracts on cell viability was assessed by 3-(4,5-dimethylthiazol-2-yl)-2,5-diphenyltetrazolium bromide) MTT assay. Briefly, PBMC $\left(5 \times 10^{5}\right.$ cells/ ml) were seeded in RPMI-1640 medium in a 96-well plate. After overnight incubation the cells were treated with fractions obtained from D. stramonium at different concentrations. Concanavalin A (Con A) $(10 \mu \mathrm{g} / \mathrm{ml})$ treated PBMC and DMSO treated $\mathrm{PBMC}$ were used as positive and negative controls respectively. The plates were incubated in $37^{\circ} \mathrm{C}, 5 \% \mathrm{CO}_{2}$ for $48 \mathrm{~h}$. For MTT assay, $10 \mu \mathrm{l} \mathrm{MTT} \mathrm{(5}$ $\mathrm{mg} / \mathrm{ml}$ ) was added into each well to generate formazan, and then cells were incubated in humidified atmosphere with $5 \% \mathrm{CO}_{2}$ at $37^{\circ} \mathrm{C}$ for $4 \mathrm{~h}$. After removing the supernatant, $100 \mu \mathrm{DMSO}$ was added to dissolve the purple crystal. The optical density of each well was measured at $595 \mathrm{~nm}$ by a microplate reader. Each experiment was performed in triplicates for three times. The percentage of proliferation was calculated by the following formula:

$$
\% \text { Proliferation }=(\mathrm{OD} \text { sample }-\mathrm{OD} \text { control }) / \mathrm{OD} \text { control } \times 100
$$

\section{Co-culture MTT micro-cytotoxicity assay}

Cancer cell lines A549 and MCF-7 (Target-T) seeded into the 96-well plate and cultured at $37^{\circ} \mathrm{C}$ in an atmosphere of $5 \% \mathrm{CO}_{2}$ to allow them to adhere overnight. PBMC (Effectors-E) were treated with fraction-10 at $10 \mu \mathrm{g} / \mathrm{ml}$ for $48 \mathrm{~h}$. After $48 \mathrm{~h}$ incubation treated PBMC were washed twice and cultured with cancer cell lines A549 and MCF-7 at several E:T ratios $(1: 2.5,1: 5,1: 10$ and $1: 20)$ and incubated in $37^{\circ} \mathrm{C}, 5 \% \mathrm{CO}_{2}$ for another $24 \mathrm{~h}$. After the co-culture incubation period, $150 \mu \mathrm{l}$ media and the suspended cells were discarded and washed twice with media. After that, $20 \mu \mathrm{l}$ of MTT at $5 \mathrm{mg} / \mathrm{ml}$ was added into each well containing $180 \mu \mathrm{l}$ media and incubated for $4 \mathrm{~h}$ in $\mathrm{CO}_{2}$ incubator. $150 \mu$ lof medium with MTT was removed from every well and $100 \mu \mathrm{LMSO}$ was added to each well to solubilise the formazan crystal by incubating for $20 \mathrm{~min}$ in $\mathrm{CO}_{2}$ incubator. Finally, the plate was read at $595 \mathrm{~nm}$ wavelength by using ELISA Reader. $^{17}$

\section{Determination of extra-cellular IFN- $\gamma$ and IL-2}

The secretion of IFN- $\gamma$ and IL-2 was analyzed using cytokine ELISA kit (BD Biosciences). PBMC were treated with fraction-10 at $10 \mu \mathrm{g} / \mathrm{ml}$ for $48 \mathrm{~h}$. The supernatant from control and treated PBMC were subjected to ELISA for the determination of extracellular IFN- $\gamma$ and IL-2 level as per kit instructions.

\section{Statistical analysis}

Data represents the results of three independent experiments done in triplicates; standard deviation and level of significance ( $p$ value) were calculated by using Graph Pad QuickCalc: t test with the help of statistical software Graph Pad Prism version 6.0. The values were considered significant when $\mathrm{p}<0.05$.

\section{RESULTS}

\section{Bioassay guided fractionation}

The immunomodulatory activity of non-alkaloid and alkaloid fractions was analyzed by MTT assay. The data revealed that non-alkaloid fraction significantly enhance proliferation of human PBMC at higher concentration $(100$ and $200 \mu \mathrm{g} / \mathrm{ml})$ after $48 \mathrm{~h}$ of incubation (Figure $1 \mathrm{~A})$. Therefore non-alkaloid fraction was further chromatographed and four broad range sub fractions were collected.

PBMC proliferation assay suggested that sub fraction-2 possesses significantly higher $(69 \pm 0.6 \%)$ immunostimulating capability at $10 \mu \mathrm{g} / \mathrm{ml}$ as compared to other fractions (Figure 1B). The sub fractions-1, 3 and 4 showed only $38 \pm 2.6,34 \pm 3.1$ and $36 \pm 2.4 \%$ proliferation respectively at $10 \mu \mathrm{g} / \mathrm{ml}$. 


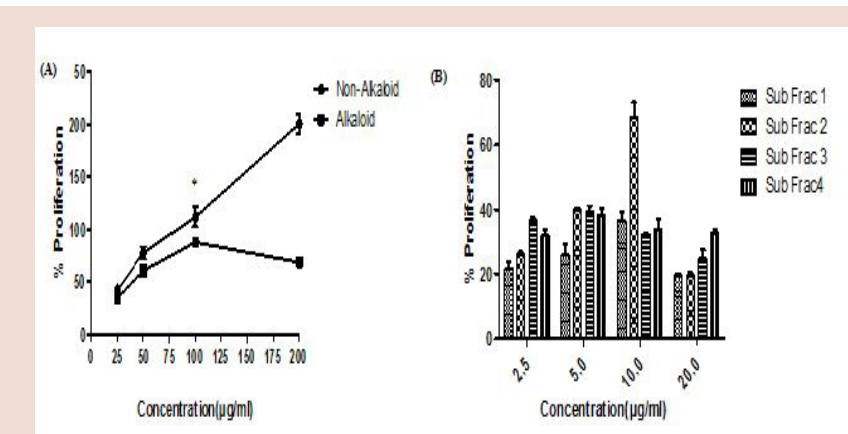

Figure 1: (A) Effect of non-alkaloid and alkaloid fractions on human PBMC proliferation at concentrations $25-200 \mu \mathrm{g} / \mathrm{ml}$ (B) PBMC treated with sub fractions at concentrations $2.5-20 \mu \mathrm{g} / \mathrm{ml}$ for $48 \mathrm{~h}$.

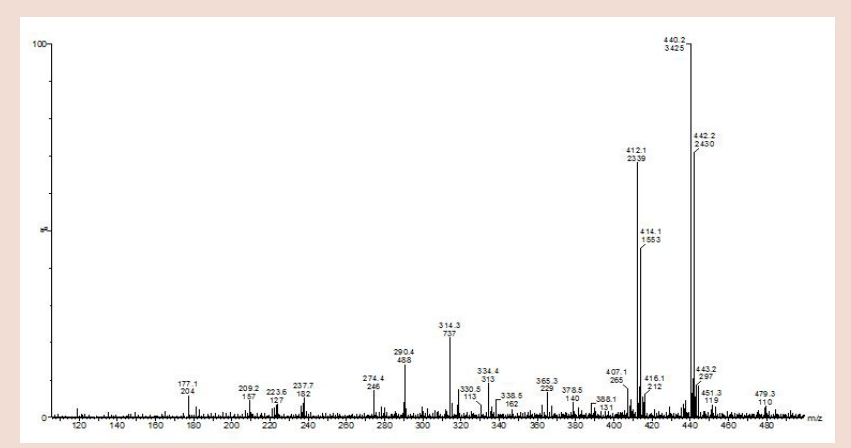

Figure 2: LC-MS chromatogram of fraction-10 from D. stramonium.

Table 1: Effect of thirteen fractions on the human PBMC proliferation.

\begin{tabular}{cc}
\hline Fractions & $\mathrm{EC}_{50}(\mu \mathrm{g} / \mathrm{ml})$ \\
\hline Con A & $26.7 \pm 0.47$ \\
Frac-1 & $75.5 \pm 2.1$ \\
Frac-2 & $56.3 \pm 2.3$ \\
Frac-3 & $76.7 \pm 3.1$ \\
Frac-4 & $50.6 \pm 1.7$ \\
Frac-5 & $45.1 \pm 2.4$ \\
Frac-6 & $66.6 \pm 1.3$ \\
Frac-7 & $75.3 \pm 2.7$ \\
Frac-8 & $90.3 \pm 1.6$ \\
Frac-9 & $47.2 \pm 1.9$ \\
Frac-10 & $19.1 \pm 1.5$ \\
Frac-11 & $42.7 \pm 2.1$ \\
Frac-12 & $47.3 \pm 1.5$ \\
Frac-13 & $41.1 \pm 1.5$ \\
\hline
\end{tabular}

The sub fraction-2 was rechromatographed in thirteen narrow range fractions. On the basis of proliferation bioassay, among 13 fractions, fraction-10 showed significantly higher mitogenic activity at a concentration range of $10-40 \mu \mathrm{g} / \mathrm{ml}$ in a dose dependent manner after $48 \mathrm{~h}$ of incubation (data not shown). The highest proliferation was exhibited by fraction-10 at $10 \mu \mathrm{g} / \mathrm{ml}$ with $\mathrm{EC}_{50}$ (half maximal effective concentration) value $19.1 \pm 1.5 \mu \mathrm{g} / \mathrm{ml}$ when compared to Con A (standard T cell activa-
Table 2: Preliminary identification of phytoconstituents from D. stramonium fraction-10

\begin{tabular}{cc}
\hline Phytochemical constituents & Fraction-10 \\
\hline Alkaloids & - \\
Carbohydrates & - \\
Terpenoids & + \\
Steroids & + \\
Flavonoids & - \\
Tannins & - \\
\hline$+=$ Present, $-=$ Absent.
\end{tabular}

(A)

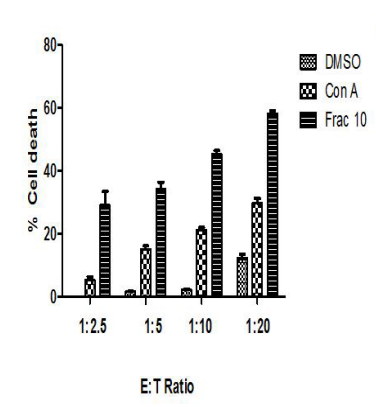

Figure 3: (A) Effect of DMSO, Con A $(10 \mu \mathrm{g} / \mathrm{ml})$ and fraction-10 treated PBMC on the cell death of A549 cancer cell line at different E:T ratios and (B) Similarly cell death was assayed in MCF-7 cancer cell line.
(A)

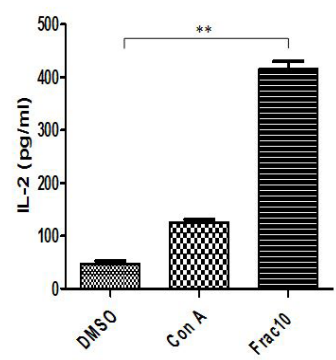

(B)

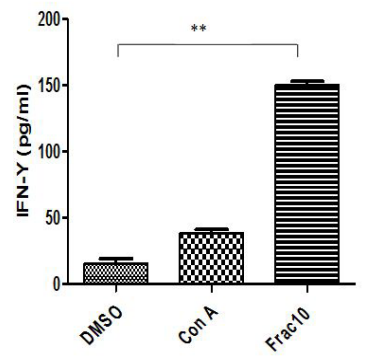

Figure 4: Cytokine induction was measured after $48 \mathrm{~h}$ treatment of human PBMC with controls and fraction- $10(10 \mu \mathrm{g} / \mathrm{ml})$. (A) IL-2 levels and (B) IFN- $\gamma$ levels.

tor $)^{18}$ having $\mathrm{EC}_{50}$ value $26.7 \pm 0.47 \mu \mathrm{g} / \mathrm{ml}$. Table 1 shows $\mathrm{EC}_{50}$ values of all thirteen fractions as determined by human lymphocyte proliferation assay.

Further preliminary phytocompound analysis showed the presence of terpenoids and steroids in fraction-10 (Table 2).

LC-MS characterization of bioactive fraction-10

LC-MS spectral data of fraction-10 showed abundant presence of two triterpenoids, daturaolone and daturadiol with corresponding $\mathrm{m} / \mathrm{z}$ of 440 (45\%) and 442 (18\%) respectively. Besides two steroids; stigmasterol $(\mathrm{m} / \mathrm{z} 412)(15 \%)$ and sitosterol (m/z 414) (10\%) were also identified ${ }^{15}$ (Figure 2).

\section{Co-culture anticancer effect of activated PBMC}

As shown in Figure 3A fraction-10 $(10 \mu \mathrm{g} / \mathrm{ml})$ treated PBMC showed $59 \pm 2.1 \%$ cell cytotoxicity towards A549 lung adenocarcinoma at 1:20 
ratio after $24 \mathrm{~h}$ whereas DMSO treated PBMC (negative control) showed only $11 \pm 3.1 \%$ cytotoxicity. Similarly when MCF-7 cells were taken as target cells, fraction-10 treated PBMC exhibited highest cytotoxicity $(62 \pm 2.3 \%)$ at $1: 20 \mathrm{E}: \mathrm{T}$ ratio as compare to DMSO treated PBMC (Figure $3 \mathrm{~B}$ ). These anticancer effects shown by fraction-10 stimulated PBMC were even higher than the PBMC treated with Con A which is known stimulating agent of T cells. ${ }^{18}$

\section{Production of cytokines}

Pre exposure to fraction-10 increased IL-2 ( 8 fold) and IFN- $\gamma$ (10 fold) production by human PBMC after $48 \mathrm{~h}$ of incubation as compare to the control treated PBMC (Figure 4).

\section{DISCUSSION}

It has been reported earlier that non-alkaloids and alkaloids from medicinal plants exhibited substantial immunostimulating activity ${ }^{8,19-21}$ therefore methanolic extract of the $D$. stramonium leaves was fractionated into non-alkaloid and alkaloid fractions. MTT assay revealed that non-alkaloid fraction possess immunostimulatory effect on human lymphocytes. Further non-alkaloid fraction was chromatographed and eluted into four broad range sub fractions. Initially the bioactivity of these four sub fractions was analysed at a concentration range of $25-200 \mu \mathrm{g} / \mathrm{ml}$ and it was found that at higher concentration these sub fractions were cytotoxic towards human PBMC whereas at a lower concentration range $(2.5-20 \mu \mathrm{g} / \mathrm{ml})$ these sub fractions enhanced human PBMC proliferation. This phenomenon has been reported earlier where immunomodulator demonstrated cytotoxic activity at higher concentrations and increased cell proliferation at lower concentrations. ${ }^{22}$ Data revealed that sub fraction 2 showed higher immunostimulatory activity $(69 \pm 0.6 \%)$ at $10 \mu \mathrm{g} / \mathrm{ml}$ as compared to other sub fractions leading to rechromatographic fractionation of the sub fraction 2 into thirteen narrow range fractions. All thirteen fractions were subjected to MTT assay that led to identification of the fraction- 10 which exhibited highest mitogenic activity $\left[\mathrm{EC}_{50}=19.1 \pm 1.5(\mu \mathrm{g} / \mathrm{ml})\right]$. Fraction-10 was further analysed for phytochemical screening and data showed the presence of terpenoids and steroids. It has been proved in the literature that terpenoids and steroids from medicinal plants possess immunomodulatory activities. ${ }^{23-25}$ Triterpenoids like lupeol, ursolic acid, oleanolic acid, betulinic acid have been shown to exhibit immunostimulatory effects both on mouse models and on human PBMC. ${ }^{23,25,26}$ In addition, LC-MS study bring about identification of four major phytocompounds in the fraction-10 as daturaolone, daturadiol, stigmasterol and sitosterol. Earlier it has been reported in literature that daturaolone could affect immune system as they were able to elicit anti inflammatory responses in mouse mode ${ }^{27}$ whereas daturadiol has shown anticancer activities. ${ }^{28}$ Similarly, stigmasterol and sitosterol have been studied for their immunostimulatory activity on human PBMC and mouse model. ${ }^{24,29}$ Taken collectively our findings and earlier reports suggest that these four major phytoconstituents identified in fraction-10 might be responsible for the enhanced proliferation of the human PBMC.

To evaluate anticancer immune responses generated by PBMC pretreated with fraction-10, we performed MTT microcytotoxicity assay. In such an assay system, target cell lysis was induced by interaction between immune cells and target cells that mimics in vivo conditions where immune cells interact with cancer cells leading to their cell death. ${ }^{17,30}$ As lung and breast cancer are the most common cancers worldwide found in males and females respectively, ${ }^{31}$ therefore A549 and MCF-7 were chosen as representative cancer target cells. Data revealed that pretreated PBMC exhibited enhanced cytotoxicity towards A549 and MCF-7 (59\% $\pm 2.1 \%$ and $62 \% \pm 2.3 \%$ at $1: 20$ effector:target ratio respectively). Co-culture MTT microcytotoxicity assay showed that both activated and non-activated
PBMC could induce the immune cells cytotoxic effects on cancer cells. PBMC contain T-cells, B cells and natural killer cells (NK) at a ratio of 80,10 and $10 \%$ respectively ${ }^{32}$ and it has been mentioned in the literature that NK and cytotoxic T lymphocytes (CTL) are involved in killing of cancer cells. ${ }^{33}$ Thus the reduction in the viability of A549 and MCF-7 cells in co-culture assay may be due to the enhanced cytolytic activity of lymphocytes that have been treated with $D$. stramonium fraction- 10 .

Moreover, fraction-10 pretreated PBMC increased the production of IL- 2 and IFN- $\gamma$ by 8 fold and 10 fold respectively. Previously it has been reported that these cytokines play an important role in innate/acquired immune responses and tumor suppression ${ }^{34}$ as IFN- $\gamma$ and IL- 2 have the ability to activate immune cells including macrophages, NK cells and CTLs which have well known cancer cell killing capabilities. ${ }^{35,36}$ The increased level of IFN- $\gamma$ and IL-2 indicates that $D$. stramonium fraction-10 might be stimulating anticancer immune responses mediated through human lymphocytes. Taken together, present research explored the in vitro immunostimulatory potential of bioactive fraction-10 from D. stramonium that boosts the immune cells and enhances their anticancer abilities against human lung and breast cancer cells.

\section{ACKNOWLEDGEMENTS}

This work was supported and funded by "Pilot Project grant for Young Investigators in Cancer Biology" of the Department of Biotechnology (grant: BT/PR9613/MED/30/1260/2013). Authors appreciated Shoolini University, Himachal Pradesh for providing all the required conveniences.

\section{CONFLICT OF INTEREST}

Authors declare that there is no conflict of interest, financial or otherwise.

\section{ABBREVIATIONS USED}

PBMC: Peripheral blood mononuclear cells; MTT: 3-(4,5-di-methylthiazol-2-yl)-2,5-diphenyltetrazolium bromide; $\mathbf{E C}_{50}$ : half maximal effective concentration; CTL: cytotoxic T lymphocytes; NK: natural killer; LCMS: Liquid chromatography-mass spectrometry; IL-2: Interleukin-2; IFN- $\gamma$ : Interferon- $\gamma$; E:T: Effector:Target; A549: Human lung carcinomas; MCF-7: human breast adenocarcinomas.

\section{REFERENCES}

1. Balachandrana P, Govindarajanb R. Cancer-An ayurvedic perspective. Pharmaco Res. 2005;51(1):19-30.

2. Borchers AT, Sakai S, Handerson GL, Harkey MR, Keen CL, Stern JS, Terasawa K Gershwin ME. Shosaiko-to and other Kampo (Japanese herbal) medicines: a review of their immunomodulatory activities. J Ethnopharmacol. 2000;73(1 2):1-13.

3. Gupta S, Raghuvanshi M, Jain D. Comparative studies on anti inflammatory activity of Coriandrum sativum, Datura stramonium and Azadirachta indica. Asian J Exp Biol Sci. 2010;1(1):151-4.

4. Charpin D, Orehek J, Velardocchio JM. Bronchodilator effects of antiasthmatic cigarette smoke (Datura stramonium). Thorax. 1979;34(2):259-61.

5. Sharma P, Bhardwaj R, Yadav A, Sharma RA. Study of antioxidant activity of Datura stramonium Linn. Res J Phytochem. 2014;8(3):112-8.

6. Singh LR, Singh OM. Datura stramonium: An overview of its phytochemistry and pharmacognosy. Res J Pharmacognosy and Phytochem. 2013;5(3):143-8.

7. Ahmad, IM, Abdalla MY, Mustafa NH, Qnais EY, Abdulla FA. Datura aqueous leaf extract enhances cytotoxicity via metabolic oxidative stress on different human cancer cells. Jordan J Biol Sci. 2009;2(1):9-14.

8. Bhat BA, Dhar KL, Puri SC, Qurishi MA, Khajuria A, Gupta A, Qazi GN. Isolation, characterization and biological evaluation of Datura lactones as potential immunomodulators. Bioorg Med Chem. 2005;13(24):6672-7.

9. Daoudi A, Aarab L, Abdel-Sattar E. Screening of immunomodulatory activity of total and protein extracts of some Moroccan medicinal plants. Toxicol Ind Health. 2013;29(3):245-53

10. Yue GGL, Chan BCL, Hon P, Fung K, Leung P, Lau CBS. Immunostimulatory activities of polysaccharide extract isolated from Curcuma longa. Int J Biol Macromol. 2010;47(3):342-7. 
11. Saini RV, Wilson C, Finn MW, Wang T, Krensky AM, Clayberger C. Granulysin delivered by cytotoxic cells damages endoplasmic reticulum and activate caspase-7 in target cells. J Immunol. 2011;186(6):3497-504.

12. Yubin JI, Miao Y, Bing W, Zhang Y. The extraction, separation and purification of alkaloids in the natural medicine. J Chem Pharm Res. 2014;6(1):338-45.

13. Deodhar KA, Shinde NW. Phytochemical constituents of leaves of Celastrus Paniculatus Wild: Endangered medicinal plant. Int J Pharmacognosy Phytochemical Res. 2014;6(4):792-4.

14. Yadav M, Chatterji S, Gupta SK, Watal G. Preliminary phytochemical screening of six medicinal plants used in traditional medicine. Int J Pharm Pharm Sci. 2014;6(5):539-42.

15. Stokvis $\mathrm{E}$, Rosing $\mathrm{H}$, Beijnen JH. Liquid chromatography-mass spectrometry for the quantitative bioanalysis of anticancer drugs. Mass Spectrom Rev. 2005;24(6):887-917.

16. Rao S, Shetty S, Nalilu SK, Nalilu ML. Radioprotective properties of chitosan on cultured human lymphocytes against electron beam radiation. J App Pharm Sci. 2015;5(8):147-51.

17. Yeap SK, Alitheen NB, Ali AM. Effect of Rhaphidophora korthalsii methano extract on human peripheral blood mononuclear cell (PBMC) proliferation and cytolytic activity toward HepG2. J Ethnopharmacol. 2007;114(3):406-11.

18. Berger SL. Lymphocytes as resting cells. Methods Enzymol. 1979;58:486-94

19. Malik F, Singh J, Khajuria A, Suri KA, Satti NK, Singh S, Kaul MK, Kumar A, Bhatia A, Qazi GN. A standardized root extract of Withania somnifera and its major constituent withanolide-A elicit humoral and cell-mediated immune responses by up regulation of Th1-dominant polarization in BALB/c mice. Life Sci. 2007:80(16):1525-38.

20. Omeje EO, Osadebe PO, Nworu CS, Nwodo JN, Obonga WO, Kawamura A, Esimone CO, Proksch P. A novel sesquiterpene acid and an alkaloid from leaves of the Eastern Nigeria mistletoe, Loranthus micranthus with potent immunostimulatory activity on C57BL6 mice splenocytes and CD69 molecule. Pharm Biol. 2011;49(12):1271-6.

21. Lopes FC, Calvo TR, Colombo LL, Vilegas W, Carlos IZ. Immunostimulatory and cytotoxic activities of Indigofera suffruticosa (Fabaceae). Nat Prod Res. 2011;25(19):1796-806

22. Kumar RA, Sridevi K, Kumar NV, Nanduri S, Rajagopal S. Anticancer and immunostimulatory compounds from Andrographis paniculata. J Ethnopharmacol. 2004;92(2-3):291-5.

23. Rios J-L. Effects of triterpenes on the immune system. J Ethnopharmacol. 2010;128(1):1-14
24. Yuk JE, Woo JS, Yun CY, Lee JS, Kim JH, Song GY, Yang EJ, Hur IK, Kim IS. Effects of lactose-beta-sitosterol and beta-sitosterol on ovalbumin-induced lung inflammation in actively sensitized mice. Int Immunopharmacol. 2007;7(12):1517-27.

25. Badria FA, Mikhaeil BR, Maatooq GT, Amer MMA. Immunomodulatory triterpenoids from the Oleogum resin of Boswellia carterii birdwood. Z Naturforsch C. 2003;58(7-8):505-16.

26. Kuttan G, Poyil PK, Kanjoormana AM, Kuttan R. Inhibition of tumor progression by naturally occurring terpenoids. Pharm Biol. 2011;49(10):995-1007.

27. Rauf A, Maione F, Uddin G, Raza M, Siddiqui BS, Muhammad N, Shah SUA Khan $\mathrm{H}$, Feo VD, Mascolo N. Biological evaluation and docking analysis of daturaolone as potential cyclooxygenase inhibitor. Evid Based Complement Alternat Med. 2016;2016:4098686.

28. PeiYH, Kwon OK, Lee JS, Cha HJ, Ahn KS, Oh SR, Lee HK, Chin YW. Triterpenes with cytotoxicity from the leaves of Vernicia fordii. Chem Pharm Bull (Tokyo). 2013;61(6):674-7.

29. Bouic PJD, Etsebeth S, Liebenberg RW, Albrecht CF, Pegel K, Van Jaarsveld PP. Beta-sitosterol and beta-sitosterol glucoside stimulate human peripheral blood lymphocyte proliferation: Implications for their use as an immunomodulatory vitamin combination. Int J Immunopharmacol. 1996;18(12):693-700.

30. Kim HR, Park HJ, Park JH, Kim SJ, Kim K, Kim J. Characteristics of the killing mechanism of human natural killer cells against hepatocellular carcinoma cell lines HepG2 and Hep3B. Cancer Immunol Immunother. 2004;53(5):461-70.

31. Ferlay J, Soerjomataram I, Ervik M, Dikshit R, Eser S, Mathers C, Rebelo M, Parkin DM, Forman D, Bray F. Cancer incidence and mortality worldwide: sources, methods and major patterns in GLOBOCAN 2012. Int J Cancer. 2015;136(5):E359-86.

32. Abbas AK, Lichtman AH, Pober JS. Cellular and molecular immunology, $4^{\text {th }}$ Ed. W.B. Saunders Company, Philaldelphia, p. 19;2000.

33. Wahlberg BJ, Burholt DR, Kornblith P, Richards TJ, Bruffsky A, Herberman RB, Vujanovic NL. Measurement of NK activity by the microcytotoxicity assay (MCA): a new application for an old assay. J Immunol Methods. 2001;253(1 2):69-81.

34. Pestka S, Krause CD, Walter MR. Interferons, interferon-like cytokines, and their receptors. Immunol Rev. 2004;202(1):8-32.

35. Lam HY, Yusoff K, Yeap SK, Subramani T, AbdAziz S, Omar AR, Alithee NB Immunomodulatory effects of newcastle disease virus AF2240 strain on human peripheral blood mononuclear cells. Int J Med Sci. 2014;11(12):1240-7.

36. Antony GK, Dudek AZ. Interleukin 2 in cancer therapy. Curr Med Chem. 2010;17(29):3297-302.

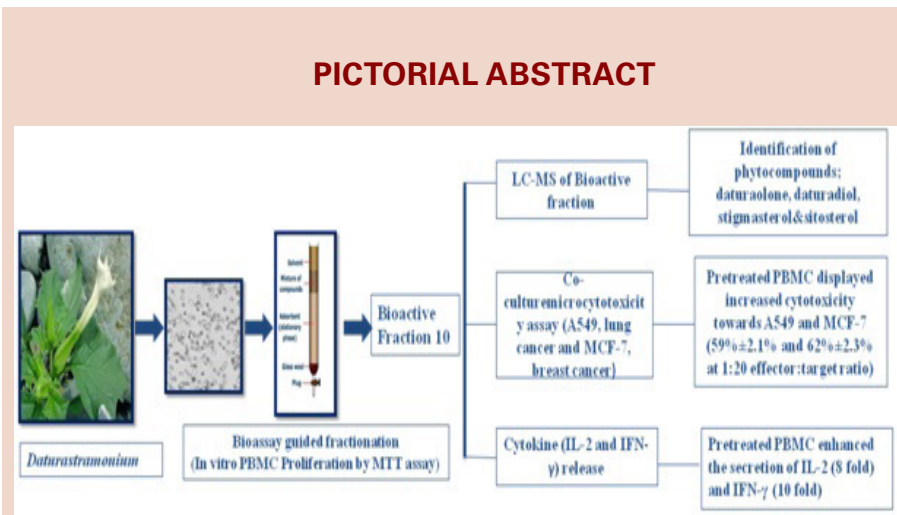

\section{SUMMARY}

- Bioassay guided fractionation of D. stramonium leaves resulted into bioactive fraction (fraction-10) exhibiting significant immunostimulatory activity $\left[E C_{50}=19.1 \pm 1.5(\mu \mathrm{g} / \mathrm{ml})\right]$ on human blood lymphocytes.

- Preliminary phytochemical analysis of fraction-10 showed the presence of terpenoids and steroids and LC-MS analysis depicted presence of four major phytoconstituents in fraction-10 as daturaolone, daturadiol, stigmasterol and sitosterol.

- Fraction-10 pretreated PBMC displayed increased cytotoxicity towards A549 and MCF-7 $(59 \% \pm 2.1 \%$ and $62 \% \pm 2.3 \%$ at $1: 20$ effector:target ratio respectively).

- Fraction-10 enhanced the secretion of IL-2 (8 fold) and IFN- $\gamma$ (10 fold) by human PBMC.

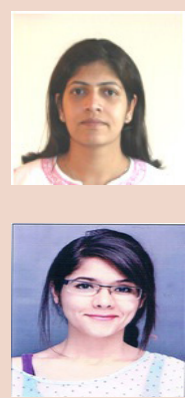

\section{ABOUT AUTHORS}

Dr. Reena V. Saini: Is an Assistant Professor at Faculty of Applied sciences and Biotechnology, Shoolini University (H.P.). She is a post-doc from National Cancer Institute, National Institutes of Health, USA. Her area of expertise are Animal Biotechnology, Immunology and Cancer biology. She also received 'Pilot Project Grant for Young Investigators in Cancer Biology' from Department of Biotechnology, India. Presently, she is working on cancer immunology and plant based immunotherapy.

Aditi Gupta: Is pursuing Ph.D. Biotechnology at Faculty of Applied sciences and Biotechnology, Shoolini University (H.P.). Her research is focused on evaluation of immunomodulatory activity of D. stramoniumLinn, and immune cells mediated cytotoxicity towards cancer cells. 